\title{
Experimental assessment of the lean blow-off in a fully premixed annular combustor
}

\author{
R. Ciardiello ${ }^{\mathrm{a}, *}$, A. W. Skiba ${ }^{\mathrm{a}}$, R. L. Gordon ${ }^{\mathrm{b}}$, E. Mastorakos ${ }^{\mathrm{a}}$ \\ ${ }^{a}$ Department of Engineering, University of Cambridge, Cambridge, UK \\ ${ }^{b}$ Department of Mechanical Engineering, School of Engineering, The University of Melbourne, Parkville, Victoria 3010, Australia
}

\begin{abstract}
The behaviour of the flame in an annular combustor with multiple bluff-body injectors with swirl was investigated to provide insights into lean blow-off (LBO) mechanisms when flames interact. Two different configurations, with 12 and 18 burners, and various bulk velocities and equivalence ratios were tested. Flame shape and main features were studied by means of $5 \mathrm{kHz} \mathrm{OH}$ chemiluminescence imaging and the stability limits were identified and compiled into stability regime diagrams. As the equivalence ratio of the mixture was reduced the individual flames would first exhibit a transition from a stable "W-shape" state to a stable "V-shape" state before becoming unstable close to extinction. In the 18-burner configuration LBO was characterised by random detachment and re-stabilisation of the flames over multiple burners across the chamber, until complete lift-off. In the 12-burner configuration the flame anchors on a few burners in azimuthally symmetric locations, making the overall flame less prone to global extinction. Finally, the stability curves were computed using a correlation based on the Damkhöler (Da) number and compared to single burner configurations. The beginning of the blow-off transient was found to be similar to the LBO condition for a single burner in the 12-burner setup, while the 18-burner configuration was less stable for all the conditions investigated. However, it was found that correlations based on single burner extinction data do not fully work for the extinction of interacting flames. The results provide insights into the blow-off of realistic gas turbine engines and can be used for validating models of such processes.
\end{abstract}

Keywords: Lean Blow-Off, Annular Combustor, Turbulent Premixed Flames, Flame Stability, Gas Turbines

\section{Introduction}

In order to reduce the formation of pollutants, namely soot and $\mathrm{NO}_{X}$, aircraft propulsion systems are considering lean premixed combustion [1]. Nevertheless, designing and developing engines that stabilise lean premixed flames in a manner that avoids detrimental phenomena such as combustion instabilities, flashback, and lean blow off (LBO) is a considerable challenge. Often, such flames are anchored within a low-velocity region formed downstream of bluff bodies and/or swirlers (i.e. within recirculation zones). The stable operating limits of a single burner have been widely studied for different configurations [2-9]. However, real combustion engines employ multiple burner configurations. The effect of the interaction between adjacent burners

\footnotetext{
* Corresponding author

Email address: rc733@cam.ac.uk (R. Ciardiello)
}

on the flame shape in an annular combustor was evaluated by Worth and Dawson $[10,11]$ and by Durox et al. $[12,13]$. Flame merging in the inter-burner region and alternating patterns were found, depending on flaring angle and swirl direction. Evidence of side recirculation zones and alternating flow patterns, depending on the inter-burner spacing, were also reported in numerical simulations of non reacting flow in an array of burners $[14,15]$. Moving from a stable configuration to the transient phenomenon of extinction, it is therefore possible to expect that the interaction between adjacent burners can significantly affect the flame behaviour when approaching blow-off conditions.

There is a lack of studies in the literature regarding the experimental investigation of stability limits of a full, laboratory scale, annular combustor. Simpler configurations have, however, been studied. For instance, Kariuki et al. [16] explored flame stability and duration of the blow-off event in a dual bluff-body stabilised burner, with and without swirl. Recently, Kwong and 
Steinberg [17] reported the flame dynamics close to extinction in an array of five burners, highlighting a transient pattern of detachment and reattachment of individual flames at blow-off conditions. Moreover, in the same configuration, it was found that a two-burner configuration resulted in improved stability compared to a single burner and to a five-burner array [18]. Also, the five-burner system proved to be less stable than a single burner setup, which was attributed to the increase in strain rate and weakening of the side recirculation zone due to flame interactions.

While such efforts provide insight into this problem, the question of whether or not such findings can be scaled up to a full configuration still remains. The annular combustor employed in this study was previously investigated in terms of thermoacoustic instabilities $[10,11,19]$ and transient process of ignition and lightround [20], and some preliminary results about the extinction behaviour of the flame were reported by Allison et al. [21]. Building upon previous research, this work explores the global structure and dynamics of premixed flames stabilised in the annular combustor of Allison et al. [21] as lean blow-off is approached. Thus, this work aims to elucidate the phenomena of flame stability within a premixed, annular combustor. Two different burner configurations were employed: one with 18 burners and the other with 12 burners. which allows a further exploration of the effects of inter-burner spacing and burner symmetry LBO. High-speed $\mathrm{OH}^{*}$ imaging was employed to visualise the global structure of the flames as LBO was approached. Additionally, conventional video cameras (operating at $60 \mathrm{~Hz}$ ) were used for online monitoring of the blow-off process.

\section{Experimental Apparatus and Methods}

This section first describes the apparatus and then the approach used to assess the stability limits of the annular combustor, along with the system employed for high speed imaging of $\mathrm{OH}^{*}$ chemiluminescence

\subsection{Fully premixed annular combustor}

The premixed annular burner employed in this study was adapted from previous works by Worth and Dawson $[10,11]$ and Allison et al. [21]. Thus, for the sake of brevity, only a brief description of this burner is given here. A schematic of this burner is provided in Fig. 1.

As Fig. 1 depicts, the burner consisted of an annular chamber with equally spaced bluff-body burners. Unlike in Refs. [10, 11], here the whole combustor was mounted horizontally, which more closely resembles aviation gas turbine combustors. Air delivered from the compressor of the lab and methane (99.5\% pure) were mixed upstream and fed into a common cylindrical plenum that was $200 \mathrm{~mm}$ long and had an inner diameter of $212 \mathrm{~mm}$. A bed of $6 \mathrm{~mm}$ diameter glass marbles was placed inside the plenum to homogenise the flow. Additionally, a honeycomb flow straightener was added just downstream of the glass marbles to ensure the flow was uniform prior to reaching the individual burners. Preliminary velocity measurements with a pitot tube (not reported here) confirmed the mixture velocity was the same for each burner. A 140-mm diameter hemispherical body, positioned at the end of the plenum, was used to evenly split the gaseous mixture into each individual burner. These burners (see Fig. 1c consisted of a $150 \mathrm{~mm}$ long cylindrical pipe with an inner diameter of $D=18.9 \mathrm{~mm}$. Conical bluff-bodies with diameters and half angles of $D_{b b}=13 \mathrm{~mm}$ and $45^{\circ}$, respectively, were fitted at the centre of each burner. Thus, the resulting blockage ratio at the exit of each burner was $50 \%$. Just upstream of each bluff body was a swirler composed of a set of six vanes (exit vane angle $\alpha=60^{\circ}$ ), which induce a counter-clockwise radial flow with a geometrical swirl number of 1.22 [11]. A $203 \mathrm{~mm}$ diameter quartz glass cylinder $145 \mathrm{~mm}$ long provided the outer boundary of the annular enclosure, while the inner boundary was provided by a steel cylinder with a diameter of 127 $\mathrm{mm}$.

Burners were held in position by two plates, such that the bluff bodies were arranged around a circle of 170 $\mathrm{mm}$ diameter. In order to investigate the effect of interburner spacing, and thus adjacent burner interactions, on LBO, two different set of plates with the same circumference were manufactured. It was thus possible to perform the study on the 12- and the 18-burner configurations, characterised by flame separation distances $\mathrm{S}_{12}=2.33 \mathrm{D}$ and $\mathrm{S}_{18}=1.56 \mathrm{D}$ respectively, evaluated as the arc distance between two adjacent bluff-body centres, as shown in Fig. 1b. Three Alicat mass flow controllers, with an accuracy of $0.8 \%$ of the set value, were used to deliver the fuel and air to the burner. The flame was ignited by an electrical spark device, recently developed in our group, which consisted of two $0.5 \mathrm{~mm}$ stainless steel electrodes with a spark gap of $2 \mathrm{~mm}$, connected to a high-voltage transformer $(2 \times 5 \mathrm{kV}, 20 \mathrm{~mA})$.

\subsection{Experimental conditions and blow-off procedure}

All cases investigated are reported in Table 1. Tests were performed at a pressure of 1 bar and temperature of $293 \mathrm{~K}$. The bulk velocity reported in Table 1 was derived from the total flow rate and the combined open area from each burner. A range of bulk velocities were 


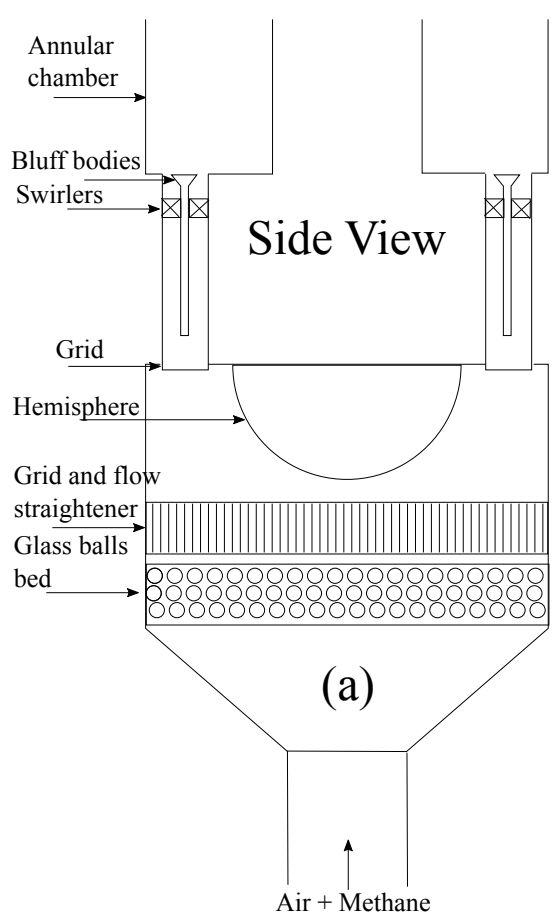

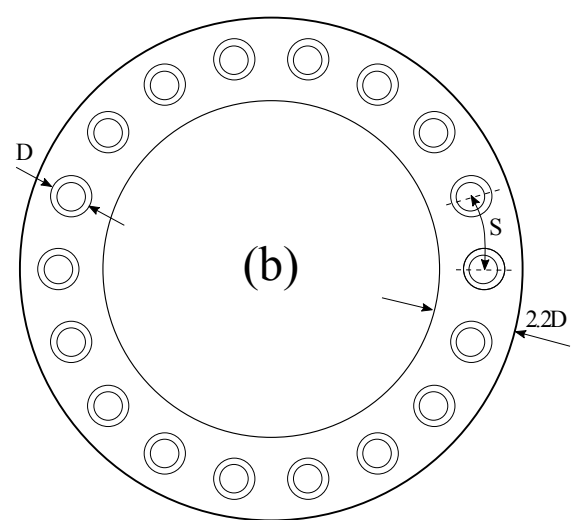

Top View

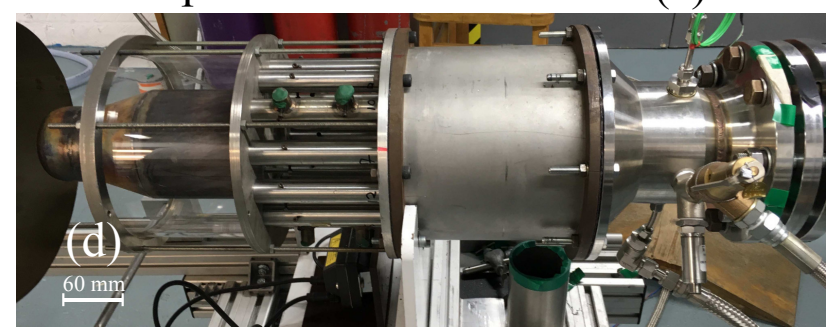

Figure 1: Schematic of the annular combustor (adapted from [10,11]), side view (a) and top view (b), and of one of the individual burners it is composed of (c). A photograph (d) shows the entire setup, including plenum, burners and combustion chamber.

used and this range differed depending on the particular burner configuration. Reaching the highest velocity in the 18-burner case used the maximum total flow rate of the facility, and thus the 12-burner configuration, which has a smaller total flow-through area, could attain higher bulk velocities.

Table 1: Flow conditions evaluated in the experimental campaign

\begin{tabular}{ccc}
\hline Configuration & $U_{\text {mix }}[\mathrm{m} / \mathrm{s}]$ & Swirl Number \\
\hline 12 Burners & $10-16-20-25-30$ & 1.22 \\
18 Burners & $10-13-16-18-20$ & 1.22 \\
\hline
\end{tabular}

The following procedure was employed to assess global flame features as LBO was approached. The mixture was ignited far from blow-off at an equivalence ratio of $\phi=0.75$, which produced stable flames for all conditions considered. Then, while keeping the air flow rate constant, the fuel flow rate was decreased such that $\phi$ was reduced by 0.02 every 20 seconds. Considered that the fuel flow rate is one order of magnitude smaller than the air flow rate, reducing methane flow rate only slightly changes the bulk velocity of the mixture, which was thus assumed constant throughout each test. For this study, a flame was considered blown-off when it de- tached completely from all the bluff bodies. However, it is noteworthy to mention that fully lifted flames could be stabilised within the burner at a distance of $\sim 5 \mathrm{~cm}$ in the axial direction away from the bluff bodies. Because such lifted flames are not desirable in most practical applications, such a burning mode is considered here as being blown-off. Finally, to provide an estimate of the repeatably of the LBO events, each test was repeated at least three times. Three conventional cameras (operating at $60 \mathrm{~Hz}$ ) were employed to monitor the flame regimes explored and the blow-off transient.

\section{3. $\mathrm{OH}^{*}$ chemiluminescence imaging}

The integrated flame structure and the flame behaviour were evaluated via high-speed imaging of $\mathrm{OH}^{*}$ chemiluminescence, which provides a reasonable estimate of the primary heat release rate regions [22]. The experimental equipment consisted of a Photron SA1.1 high-speed CMOS camera, with a maximum resolution of $1024 \times 1024$ pixels up to $5.4 \mathrm{kHz}$. Coupled to the camera was a LaVision IRO high-speed intensifier, which was gated at $180 \mu$ s for a $5 \mathrm{kHz}$ frame rate (which was used for all recordings). A UV lens (Cerco $2178)$ fitted with a narrow bandpass filter $(310 \mathrm{~nm}+/-5$ $\mathrm{nm}$ ) was attached to the IRO. For each flame condition a set of 5000 images was recorded and analysed. Two 
separate cameras were used (not simultaneously), one viewed all of the burners from the "top" (i.e. looking axially towards the burners from downstream) while the other was positioned on the side of the annular combustor and thus visualised only on the visible subset of the burners.

\section{Results and Discussion}

\subsection{Analysis of flame shape and stability regimes}

Fig. 2 reports a picture of the flame from top and side of the burner at a stable condition, using the three conventional cameras. Far from blow-off, the flame
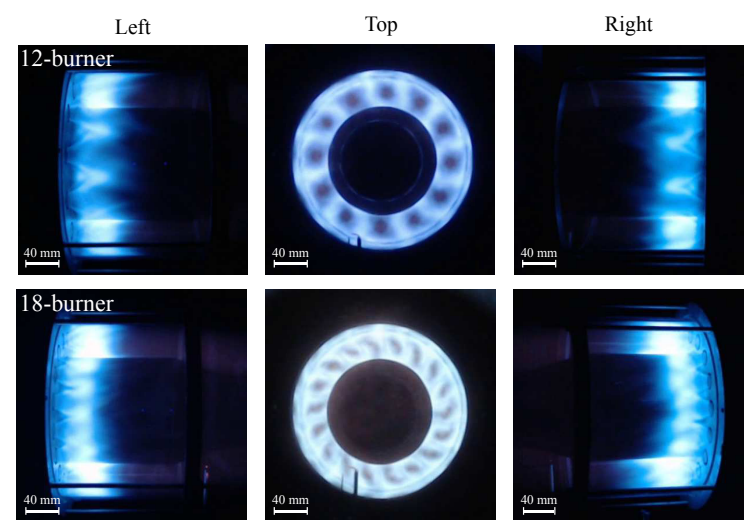

Figure 2: Images of a stable flame $\left(\phi=0.75\right.$ and $\left.U_{m i x}=16 \mathrm{~m} / \mathrm{s}\right)$ for the two different configurations, taken from the top of the burner, from the right and from the left. The 12-burner configuration is shown on the top, while the 18-burner configuration on the bottom.

is bright and steady; additionally, flame-flame interactions, in term of flames touching in the inter-burner region, were observed between each of the burners. Figure 3 shows the mean $\mathrm{OH}^{*}$ chemiluminescence, from the top of the burner, at stable conditions $(\phi=0.75)$ for the two separate burner configurations. The small rods on the bottom of each image are the spark device used for ignition. An annular mask was applied over each frame to cover reflections on the inner and the outer wall and thus showing only the annular chamber. The flame appears even and well distributed over the burners, visually suggesting that flow conditions $\left(U_{m i x}, \phi\right)$ are the same for each burner.

For the 18-burner configuration $(S=1.53 \mathrm{D})$, the swirl effect is evident on the flame shape. Individual flame brushes appear to merge in their products region between the burners (in agreement with [11, 16, 23]) and the flame globally appears to follow a counterclockwise pattern that is induced by the swirling flow. When increasing inter-burner spacing the array more closely resembles that of a series of individual burners. Although, as will be clear from side-view images, there is still presence of flame in the inter-burner region where two individual brushes appear to merge.
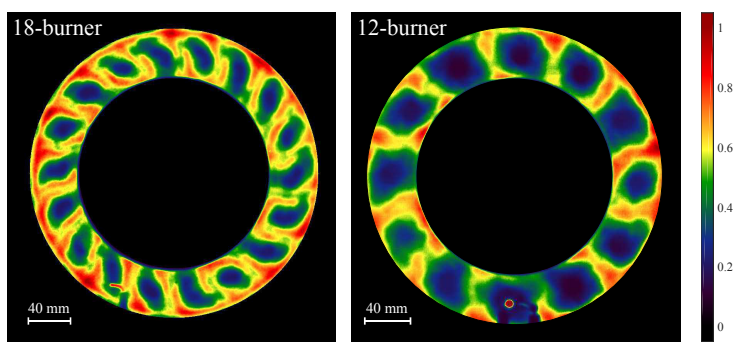

Figure 3: Average $\mathrm{OH}^{*}$ chemiluminescence images taken from a topdown view of the burner under stable conditions (i.e. $\phi=0.75$ ). The left and right images were taken from the 18- and 12-burner configurations with bulk velocities of 16 and $20 \mathrm{~m} / \mathrm{s}$, respectively. The images are normalised by the maximum pixel intensity and their relative signal levels are characterised by the colorbar.

The average side-view $\mathrm{OH}^{*}$ images are reported in Fig. 4. White lines delimit the part of the burner that is in direct line of sight of the camera, while the bright regions on the top and the bottom of each image result from the fact that the camera is integrating over multiple burners in this region. Figure 4(a) and 4(b) clearly show that, at a stable condition, in both configurations, the flame stabilises on the bluff bodies and assumes a W-shape, with a pocket of $\mathrm{OH}^{*}$ emission existing between the two burners. This suggests the presence of flame links, or flame pockets, in the interburners region. Other studies of multi-burner configurations have reported similar features (see, for example, Refs. [12, 16, 24]).

Figures 4(c) and 4(d) present average side-view $\mathrm{OH}^{*}$ images from cases with reduced equivalence ratio. It is evident from these figures that reducing $\phi$ results in a gradual shift in the flame appearance. Figures 4(c) and 4(d) show that the flame is stretched and becomes longer, while the interaction between adjacent burners progressively reduces. Thus, after a transition, the flame assumes a sort of V-Shape, behaving like a conglomerate of individual flames in the vicinity of the bluffbodies. As is evident from Fig. 4(e) and 4(f), as the equivalence ratio is reduced, there is a region above each burner that is void of $\mathrm{OH}^{*}$ signal, which is indicative of a reduction in flame-flame interactions.

The flames within both burner geometries follow a similar series of transitions as LBO was approached. Namely, as the equivalence ratio of the mixture was reduced the flames would first transition from a stable "W-shape" to a stable "V-shape". Once this transition 


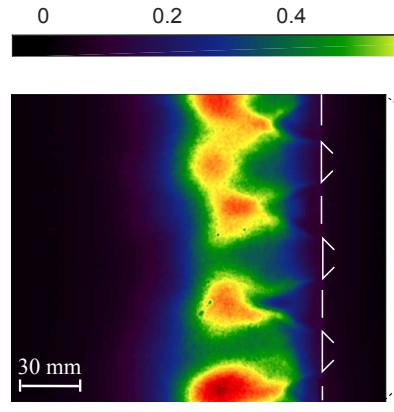

(a) 18-burner Stable flame W-Shape $\varphi=0.75 \mathrm{U}_{\text {mix }}=16 \mathrm{~m} / \mathrm{s}$

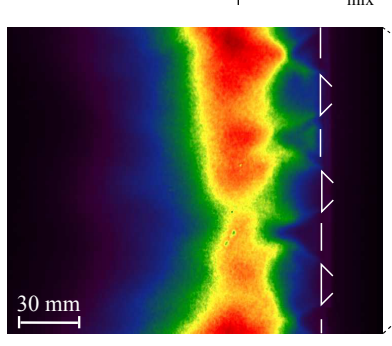

(c) 18-burner Transition W-to-V-Shape $\varphi=0.64 U_{\text {mix }}=16 \mathrm{~m} / \mathrm{s}$
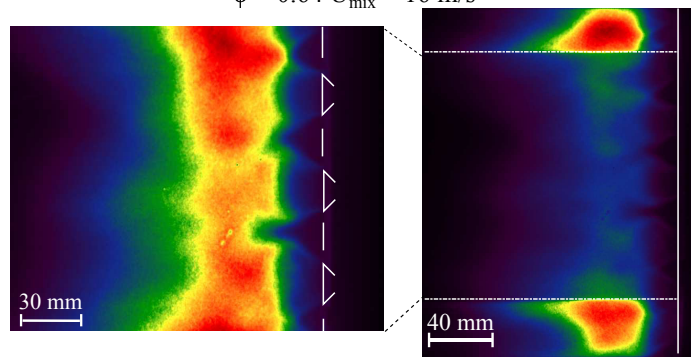

(e) 18-burner V-Shape flame $\varphi=0.62 \mathrm{U}_{\text {mix }}=16 \mathrm{~m} / \mathrm{s}$

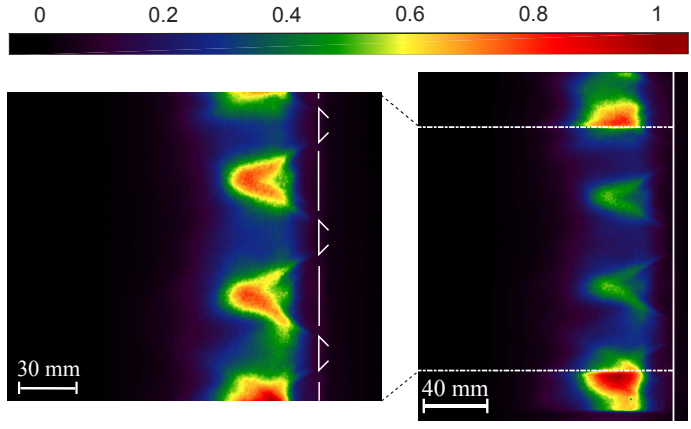

(b) 12-burner Stable flame W-Shape $\varphi=0.75 \mathrm{U}_{\text {mix }}=20 \mathrm{~m} / \mathrm{s}$

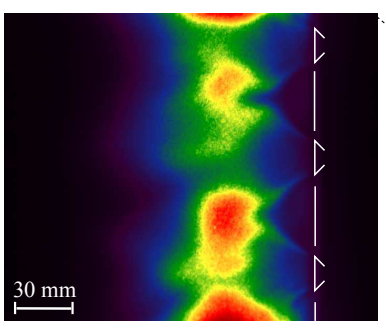

(d) 12-burner Transition W-to-V-Shape $\varphi=0.63 \mathrm{U}_{\text {mix }}=20 \mathrm{~m} / \mathrm{s}$

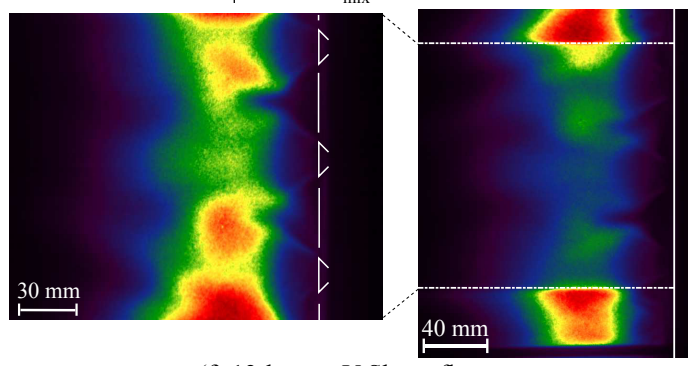

(f) 12-burner V-Shape flame $\varphi=0.61 \mathrm{U}_{\text {mix }}=20 \mathrm{~m} / \mathrm{s}$

Figure 4: Average $\mathrm{OH}^{*}$ chemiluminescence from the side of the burner. All images are normalised on the peak value. White lines outline the parts of the burner that fall within the field of view. Images on the left refer to the 18-burner configuration $\left(U_{m i x}=16 \mathrm{~m} / \mathrm{s}\right)$, while on the right the 12-burner configuration $\left(U_{m i x}=20 \mathrm{~m} / \mathrm{s}\right)$ is reported.

has occurred, further reduction of the equivalence ratio ultimately leads to global extinction of the flame. Note, however, that for a specific configuration, at a set mixture velocity and over a specific range of $\phi$, the flame exhibits a mix of blown-off/attached features. Such unstable flames are termed "close to blow-off" and are discussed in more detail in the next section.

Stability curves were produced for the separate configurations by following the procedure explained in the methods section. These curves are presented in Fig. 5 in the form of a regime diagram of the different stability regions. Increasing bulk velocity reduces the stability of the system, resulting in a rise of the equivalence ratios at which all transitions happen. Previous studies have produced stability curves for single burner configurations and their results are similar to those presented here [2, 3]. While it is evident that the flames in each configuration undergo the same transitional steps (from $\mathrm{W}$ - to $\mathrm{V}$-, to lifted, to extinguished), the stability of these separate cases is slightly different. This can be observed from Fig. 5; namely, reducing the inter-burner distance led to a shift of all transition curves toward higher equivalence ratios (i.e. reducing inter-burner spacing reduced the overall stability of the system).

A comparison of the LBO stability curves in Fig. 6 clearly shows that the flame is less prone to global extinction in the case of 12 burners. The beginning of the blow-off transient, indicated by the first detachment of 


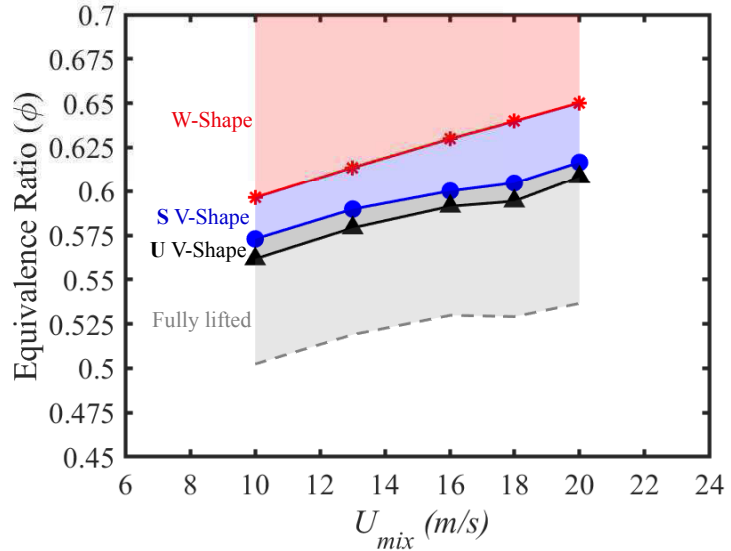

(a) Regime diagram for the 18-burner configuration

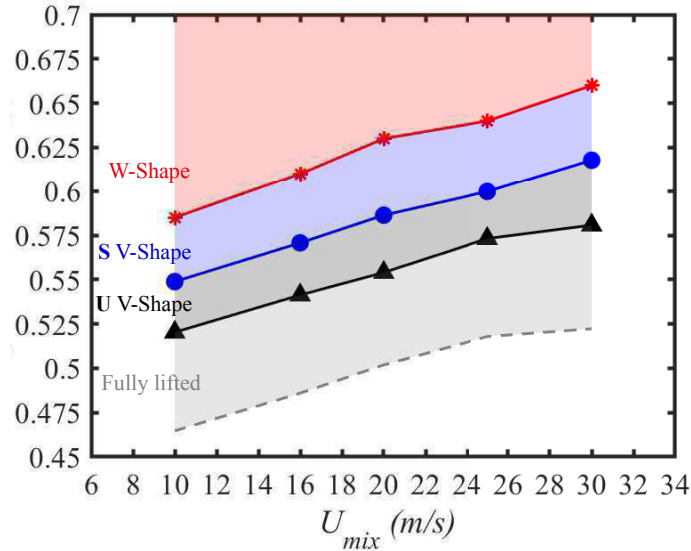

(b) Regime diagram for the 12-burner configuration

Figure 5: Regime diagrams of the different flame conditions for the two configurations. "S V-Shape" and "U V-Shape" refers to a stable and unstable condition, respectively. The grey dashed line at the bottom of each plot is the limit of complete flame extinction.

the flame over an individual burner across the chamber, was also shifted towards lower equivalence ratios when increasing the inter-burner spacing. In addition, it is possible to notice that the region where the flame is close to blow-off is broader (i.e. spans over a larger range of $\phi$ ) in the case of the 12-burner. A reason for these results was found analysing the flame kinematics when approaching LBO in the two different configurations, discussed next.

\subsection{LBO behaviour of the 18-burner configuration}

Figure 7 shows a sequence of instantaneous images taken from the side view of the annular chamber at conditions close to blow-off (dark grey region in Fig. 5(a)).

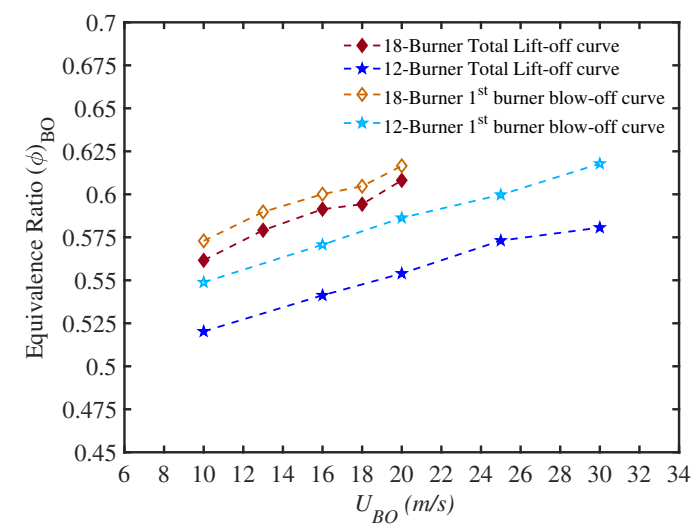

Figure 6: Limits of the beginning of the blow-off transient and lean blow-off curves (defined as complete flame lift-off) for the two configurations.
Once individual V-shaped flames form, the total flame exhibits unstable motions, highlighted in Figs. 7(a)-(c). The flame begins to detach from random burners (in the azimuthal direction) across the chamber. The lift-off of the flame from one burner leads to the gradual destabilisation of the flame on the adjacent burner and in Figs. 7(c) the flame appears completely lifted after $108 \mathrm{~ms}$ from the initial condition. Following this, the flame starts propagating back upstream. As shown in Figs. 7(d)-(f) pockets of flame and hot products are simultaneously convected upstream, re-igniting and stabilising the flame. This flame motion appears to be similar to the flame propagation pattern experienced during the ignition of an annular combustor [20].

Furthermore, such motions are dominated by the bulk swirl inside the chamber, which allows re-circulation of the hot products and permits re-ignition of individual burners. The flame jumps back and re-stabilises as a result of the interaction between all burners and the subsequent change in flow conditions associated with local extinction. This specific sequence of quenching and reignition differs from the phenomena observed in single burner configurations $[2,3]$, while it was similarly detected in a linear array of burners [17]. In Ref. [17] it was hypothesised that the local change in fluid density subsequent to the localised extinction would cause redistribution of the of mixture flow rate through adjacent burners. Namely, local lift-off over one burner would increase the mass flow rate, and thus velocity, in the adjacent burners and reduce the flow rate in the lifted burner, and vice-versa for the flame stabilisation. As a result, flame lift-off over a burner is likely to promote extinction of the surrounding burners, while flame sta- 


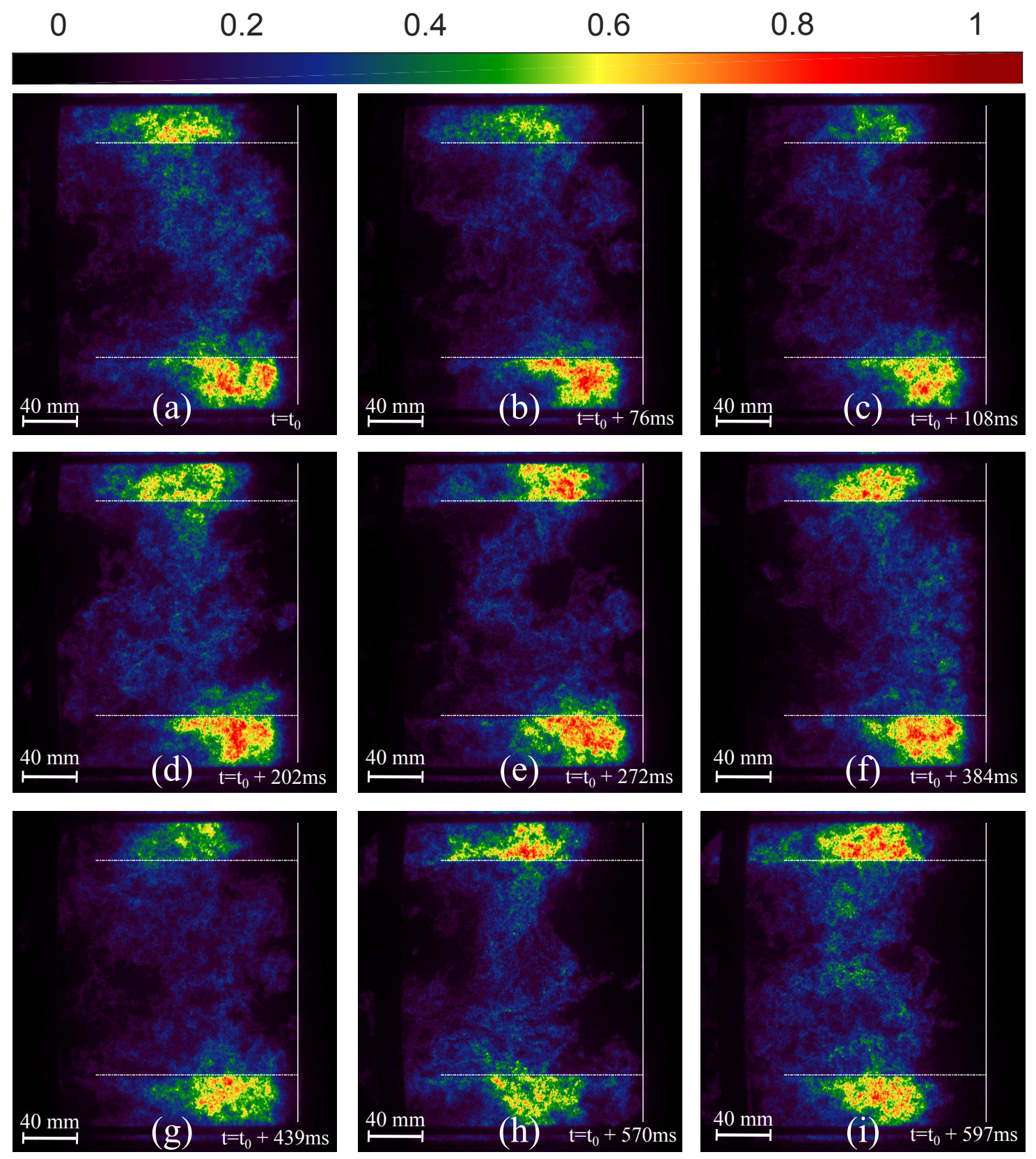

Figure 7: Sequence of instantaneous images of $\mathrm{OH}^{*}$ chemiluminescence for the 18-burner system, taken from the side view at conditions close to LBO $\left(\phi=0.61-0.59, U_{m i x}=16 \mathrm{~m} / \mathrm{s}\right)$. All images are normalised on the peak value.

bilisation would have a positive effect on the surrounding area. The results shown in this study on a full annular geometry appear to support such possible explanation. The detachment/re-attachment of the flame involves the entire annular chamber, affecting individual burners randomly. This is evident from Fig. 8, where the average $\mathrm{OH}^{*}$ images from the top and side view at conditions close to $\mathrm{LBO}$ are reported. It is possible to notice that the distribution of $\mathrm{OH} *$ is quite, albeit not perfectly, uniform across the chamber, implying there is no clear preferential location for the flame lift-off.

Eventually, after further reduction of $\phi$, the flame lifts-off completely from the burners, which is shown in Figs. 7(g)-(i). While fully lifted flames can be stabilised within this burner, such a flame configuration is typically undesirable as it could lead to over heat of the 

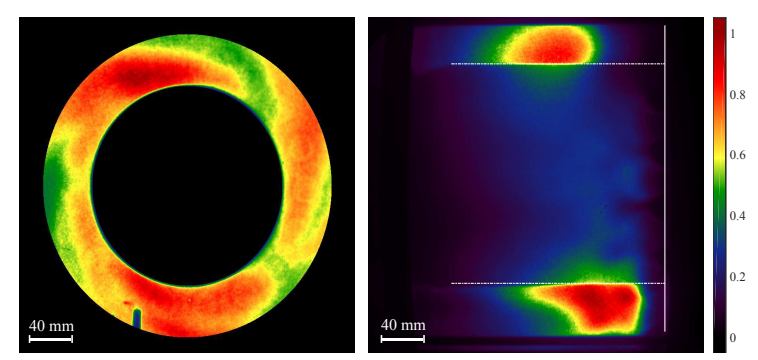

Figure 8: Mean $\mathrm{OH}^{*}$ chemiluminescence for the 18-burner configuration at conditions close to $\operatorname{LBO}\left(\left(\phi=0.6 U_{m i x}=16 \mathrm{~m} / \mathrm{s}\right)\right.$, viewed from the top (left) and the side (right).All images are normalised on the peak value.

turbine blades positioned at the exit of practical combustion chambers. Therefore, as stated previously, the full lift-off event is considered as the effective blow-off of the flame.

\subsection{LBO behaviour of the 12-burner configuration}

In general the 12-burner configuration exhibited similar behaviour to the 18-burner configuration as LBO was approached, showing a pattern of flame lift-off and re-stabilisation. However, the difference relies in the locations where this feature of detachment/re-attachment of the flame can be observed. Namely, when approaching blow-off, the flame begins to detach from some of the burners, lifting from the all bluff-bodies except from three to four azimuthal locations symmetrically located around the annular chamber. This means that the phenomenon is not randomly occurring across the chamber but appears localised on specific burners. This is clearly evident from the average $\mathrm{OH}^{*}$ images displayed in Fig. 9 at conditions close to blow-off. From the top view, the $\mathrm{OH} *$ signal appears to be concentrated in 4 regions, representing individual burners on which the flame seems to preferentially stabilise. One of these burners can be seen in the side view image.

The sequence of instantaneous images reported in Fig. 10 shows the temporal evolution of the flame over three specific burners during LBO. In Fig. 10(a) it is possible to see the flame stabilised on the middle burner (marked with a square), while is lifted off the two adjacent burners. As is evident from Fig. 10(b)-(f), multiple regions of low-level $\mathrm{OH}^{*}$ signal exist (marked with circles) and these regions are subsequently followed by region of high intensity of $\mathrm{OH}^{*}$ (marked with triangles), suggesting a continuous cycle of opening and closing of the flame front. As a result, the flame appears to be lifting and subsequently re-stabilising on the the burner. It is possible to notice that the mechanism of detachment/re-attachment is confined to the middle burner, which was previously identified as one of the 'flame pillars' that appear to anchor the flame close to blow-off.The anchored flame appears to be pushed and stabilised by the presence of the surrounding lifted flames. When the equivalence ratio is further reduced, the flame eventually lifts-off completely, as shown in Fig. 10(g)-(i). This behaviour exists throughout the annular chamber and is not a feature found in single burner geometries. The symmetry of the flame in this condition suggests the presence of a flow instability that develops inside the chamber. Further investigation is needed to evaluate the cause of this flame behaviour. It is plausible that the random anchoring of three to four burners close to LBO for the 12-burner configuration could contribute to the improved stability of this system.
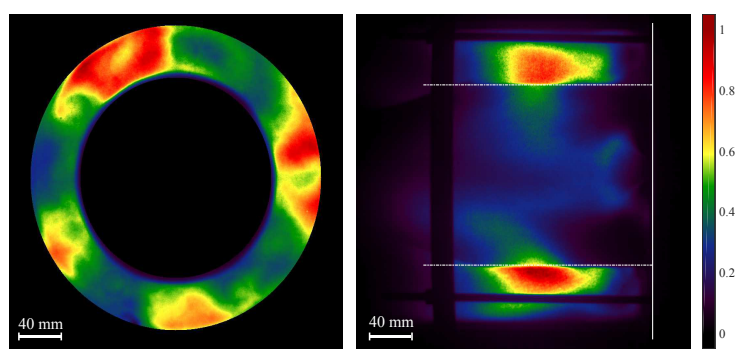

Figure 9: Mean $\mathrm{OH}^{*}$ chemiluminescence for the 12-burners configuration at conditions close to $\mathrm{LBO}\left(\left(\phi=0.58 U_{\text {mix }}=20 \mathrm{~m} / \mathrm{s}\right)\right.$, viewed from the top (left) and the side (right). All images are normalised by the peak value.

\subsection{Correlation for the blow-off conditions}

A correlation between the blow-off conditions $\left(\mathrm{U}_{B O}, \phi_{B O}\right)$ and mixture and flow properties is difficult to achieve, as these usually depend on the configuration. A simple, yet effective, correlation was proposed by Radhakrishnan et al. [25], as a result of a theoretical analysis on a single, bluff-body stabilised burner. The main assumption of their correlation is that a successful burning flame is related to the laminar flame propagation across the turbulent structures being faster than a characteristic fluid mechanic time. In case of a bluff-body stabilised flame, there are two characteristic flow times, associated with the recirculation zone and the shear layer mixing time. An extinction velocity was therefore associated with a critical $D a$ number, as a function of the chemical timescale $v / S_{L}$ and the bluff body diameter $\left(D_{b b}\right)$, as reported in Eq. 1,

$$
\frac{1}{D a}=\left[C\left(\frac{U_{m i x}}{D_{b b}} \frac{v}{S_{L}^{2}}\right)\right]^{1 / 2}
$$

where $C$ is a constant that incorporates empirical constants and the turbulence parameters, assuming they are 


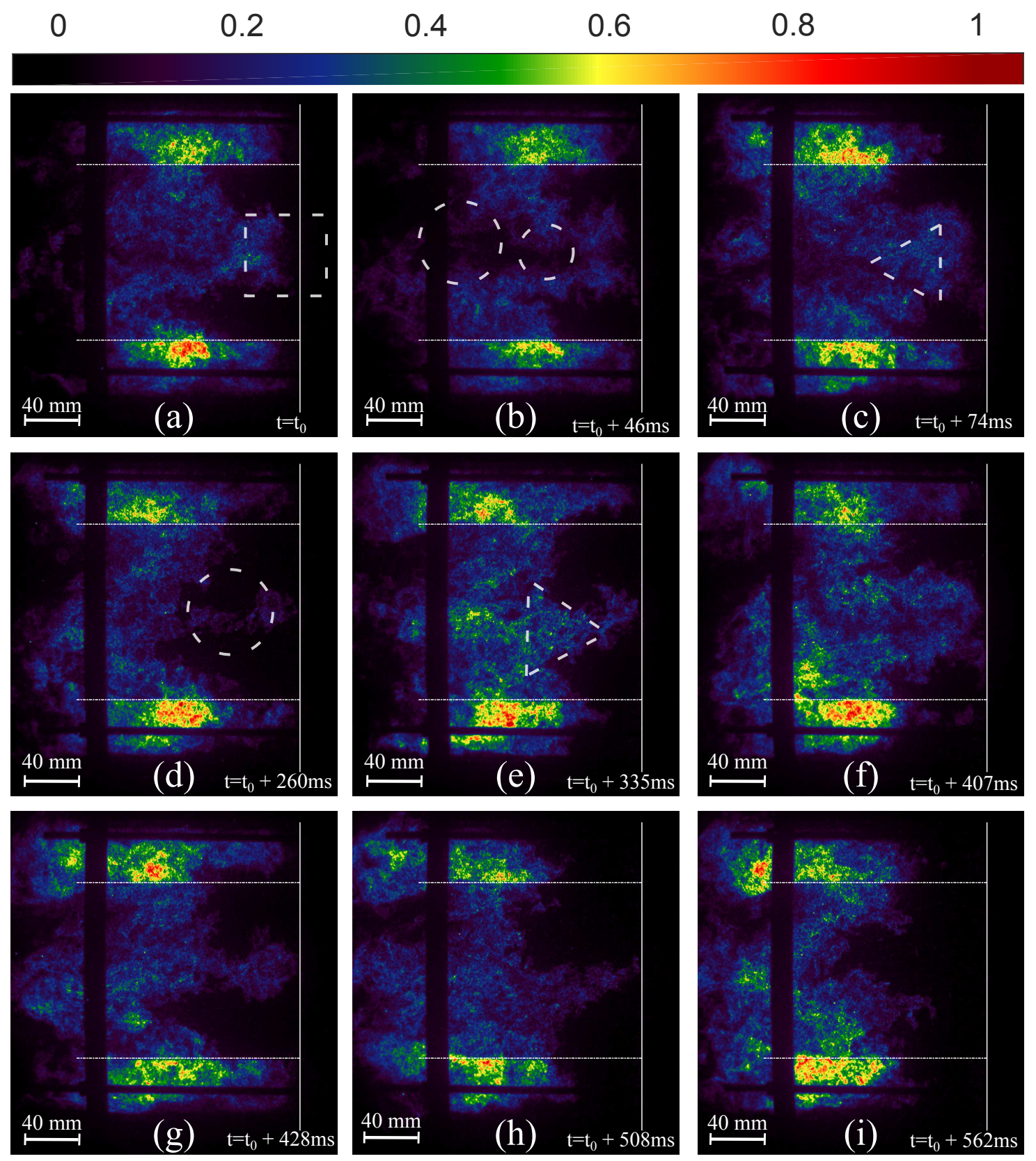

Figure 10: Sequence of instantaneous images of $\mathrm{OH}^{*}$ chemiluminescence for the 12-burners configuration, taken from the side at conditions close to LBO $\left(\phi=0.59-0.56, U_{m i x}=20 \mathrm{~m} / \mathrm{s}\right)$. All images are normalised by the peak value.

independent on the bulk velocity, and is on the order of $1, v$ is the kinematic viscosity of the mixture, $S_{L}$ the laminar flame speed and $U_{\text {mix }}$ the mixture velocity, as evaluated at the exit of the burner.

This correlation was validated over multiple experimental data of bluff-body flames [25, 27], and recently showed to be successful also for swirled bluff-body stabilised flames [26]. Therefore, it was interesting to eval- uate the stability limits of the annular combustor using eq. 1, as reported in Fig. 11. The two limits of the beginning of the blow-off transient (first burner blow-off) and the full lift-off were considered for both configurations and compared to the stability curves from a single premixed bluff-body, swirl stabilised burner, retrieved from the experiments of Kariuki [26] and Cavaliere et al. [28]. Two different swirlers were employed in that 


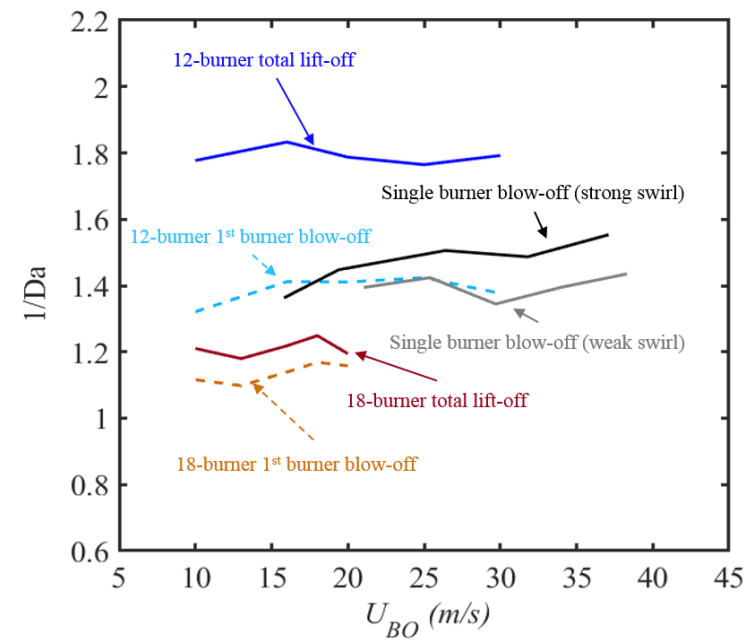

Figure 11: Stability limits of the annular combustor, in the 12-burner and 18-burner configuration, and of a single burner configuration [26], expressed in the form of critical Da number as a fuction of $\mathrm{U}_{B O}$.

work, corresponding to a $\mathrm{S}_{N}=0.77$ and $\mathrm{S}_{N}=1.25$, which were defined as weak swirl and strong swirl, respectively. Increasing the swirl intensity resulted in augmented stability for the system.

All the curves show a critical value for $D a$ in a narrow range with little variations with the blow-off velocity. This suggests that a $D a$-based scaling could be used to provide an estimate for the blow-off conditions of the flame. However, it is clear not all of the flames collapse on the same curve.

The value of $1 / \mathrm{Da}$ computed for first blow-off in the 12-burner setup was in good agreement with the experiments on single burner configurations, lying in the range of 1.3 to 1.6 for all bulk velocities. It was found that when reducing $\phi$ the flame experienced a transition to a so-called V-shape, characterised by reduced interaction between adjacent burners and absence of flame in the inter-burner region.In very lean conditions, close to the bluff-body the flame in the 12-burner system was behaving similarly to 12 individual burners and the flameto-flame interactions shifted downstream. It is therefore reasonable to assume that this phenomenon is the main cause for the initial blow-off of individual burners in this setup to be in strong agreement with single burners stability curves. In contrast, the total lift-off curve of the 12-burner was in the range 1.7-1.8, proving far more stable than every other configuration. The reason is the flame behaviour discussed in section 3.3, and the finding confirms that this configuration shows an improved stability also when compared to single burner configurations.
The same transition in flame shape was present in the 18-burner setup, however its stability behaviour is quite different in this case. The reason for both curves being at lower $1 / D a$, thus less stable, is probably related to the different level of flame interaction in this configuration. The first transition is linked to the extinction of the flame in the inter-burner region. This implies that the presence of an adjacent burner could affect flame strain between two flame brushes. In this configuration the separation was enough to grant a complete independence of each individual burner, resulting in a different stability also for the beginning of the blow-off process. It is clear that correlations based on single burner extinction data do not fully capture the extinction of interacting flames. It is likely that a different length scale may have to be used.

\section{Conclusions}

This work reports on the behaviour of premixed flames within an annular combustor as lean blow-off (LBO) was approached. Two different burner configurations were employed, one with 12 and the other with 18 burners that were evenly spaced within the annular enclosure. First, the LBO limits of these separate configurations were assessed over a range of bulk velocities. Stability curves were developed from these limits and they indicate that the 12-burner configuration, which has a smaller inter-burner spacing, is more stable for a constant local bulk flow velocity for the individual burners than the 18-burner configuration.

In addition to the separate stability curves, specific flame stability limits were identified and compiled into regime diagrams. These regime diagrams indicate that the flames within both burner geometries follow a similar series of transitions as LBO was approached. Namely, as the equivalence ratio of the mixture was reduced the flames would first transition from a stable "Wshape" to a stable "V-shape". Further reduction of the equivalence ratio would cause the V-flames to become unstable (i.e. they chaotically lift-off and re-attach to the bluff bodies) and transition into a regime referred to as "unstable V-shape." Reducing the equivalence ratio further would subsequently lead to a fully lifted flame, which was defined as "lean blow-off" in this work. Finally, at even lower equivalence ratio values, the flame would fully extinguish.

To corroborate and shed light on the flame motions in the different stability regions, high-speed $(5 \mathrm{kHz})$ $\mathrm{OH}^{*}$ imaging was implemented. Average $\mathrm{OH}^{*} \mathrm{im}-$ ages clearly showed the aforementioned flame-stability 
transitions. Furthermore, both average and instantaneous images provided insight into the reason for the 12-burner configuration being more stable than the 18burner setup. Namely, in the 12-burner configuration, 3 to 4 individual flames tended to remain attached whilst the others lifted-off. Such long-lived attachment appeared to provide additional support to the flames, thus prolonging blow-off (i.e. full lift-off). The reasons these specific burners exhibited prolonged attachment is still unknown. However, efforts are currently underway to elucidate this phenomenon. It was tried to correlate the blow-off limits using a previously developed $D a$-based correlation. A comparison with experiments on single burner systems revealed that the beginning of the blowoff event can be predicted, showing the flame when becoming leaner more resembles a set of individual burners, especially in the 12-burner configuration. The 18burner setup, in constrast, proved to be less stable due to the strong interaction between the adjacent burners.

Overall, this work yields insight into the stability limits of premixed annular combustors, which is a considerable concern for many practical, low-emission, gas turbine engines. Moreover, the results presented here highlight the importance of considering multi-burner geometries as they exhibit characteristically different features from single-burner geometries as LBO is approached.

\section{Acknowledgements}

This work has received funding from the European Union's Horizon 2020 Research and Innovation Programme under the Marie Skłodowska-Curie Grant Agreement No. 765998 as part of project "Annulight." The authors would like to thank Dr. Patton M. Allison, Dr. Pedro M. de Oliveira, and Mr. Rohit S. Pathania for their valuable suggestions regarding the operation of the annular combustor and the improvement of the experimental setup. Robert Gordon gratefully acknowledges the support of the Royal Academy of Engineering through the Newton International Fellowship alumni program, and the University of Melbourne.

\section{References}

[1] A. W. Lefebvre, D. R. Ballal, Gas Turbine CombustionAlternative fuels and emissions, CRC press, Taylor and Francis group, NY, 2010.

[2] J. Kariuki, J. R. Dawson, E. Mastorakos, Measurements in turbulent premixed bluff body flames close to blow-off, Combust. Flame 159 (2012) 2589-2607.
[3] J. R. Dawson, R. L. Gordon, J. Kariuki, E. Mastorakos, A. R. Masri, M. Juddoo, Visualization of blow-off events in bluffbody stabilized turbulent premixed flames, Proc. Combust. Inst. 33 (2011) 1559-1566.

[4] J. Kariuki, A. Dowlut, R. Yuan, R. Balachandran, E. Mastorakos, Heat release imaging in turbulent premixed methane-air flames close to blow-off, Proc. Combust. Inst. 35 (2015) 14431450 .

[5] A. Akbari, V. McDonell, S. Samuelsen, Impact of fuel composition on blow off and flashback in swirl stabilized lean premixed combustion, Proc. ASME Turbo Expo 2 (2013) 1-11.

[6] Q. An, W. Y. Kwong, B. D. Geraedts, A. M. Steinberg, Coupled dynamics of lift-off and precessing vortex core formation in swirl flames, Combust. Flame 168 (2016) 228-239.

[7] R. B. Chowdhury, B. M. Cetegen, Experimental study of the effects of free stream turbulence on characteristics and flame structure of bluff-body stabilized conical lean premixed flames, Combust. Flame 178 (2017) 311-328.

[8] B. Lewis, G. V. Von Elbe, Combustion, flames and explosion of gases, Harcourt Brace Jovanovich, London, 1987.

[9] D. Dunn-Rankin, P. Therkelsen, Lean Combustion: Technology and Control, Elsevier Science, 2016.

[10] N. A. Worth, J. R. Dawson, Self-excited circumferential instabilities in a model annular gas turbine combustor: Global flame dynamics, Proc. Combust. Inst. 34 (2013) 3127-3134.

[11] N. A. Worth, J. R. Dawson, Modal dynamics of self-excited azimuthal instabilities in an annular combustion chamber, Combust. Flame 160 (2013) 2476-2489.

[12] D. Durox, K. Prieur, T. Schuller, S. Candel, Different Flame Patterns Linked With Swirling Injector Interactions in an Annular Combustor, J. Eng. Gas Turbines Power 138 (2016) 101504

[13] K. Prieur, D. Durox, T. Schuller, S. Candel, A hysteresis phenomenon leading to spinning or standing azimuthal instabilities in an annular combustor, Combust. Flame 175 (2017) 283-291.

[14] B. Dolan, R. Villalva Gomez, E. Gutmark, Parametric Study of Alternating Flow Patterns in Non-Reacting Multiple-Swirl Flows, Flow, Turbul. Combust. 100 (2018) 437-455.

[15] M. Cordier, A. Vandel, B. Renou, G. Cabot, M. Boukhalfa, L. Exclapez, D. Barré, E. Riber, B. Cuenot, L. Gicquel, Experimental and numerical analysis of an ignition sequence in a multiple-injector burner, in: Proc. ASME Turbo Exp 2013.

[16] J. Kariuki, N. Worth, J. Dawson, E. Mastorakos, Visualisation of blow-off events of two interacting turbulent premixed flames, 51st AIAA Aerosp. Sci. Meet. Incl. New Horizons Forum Aerosp. Expo. 2013 (2013) 1-12.

[17] W. Y. Kwong, A. M. Steinberg, Blowoff and reattachment dynamics of a linear multi-nozzle combustor, J. Eng. Gas Turbines Power 141 (2018) 1-9.

[18] W. Y. Kwong, A. M. Steinberg, Effect of inter-nozzle spacing on lean blowoff performance of a linear multi-nozzle combustor, in: AiAA Scitech forum 2019, pp. 1-12.

[19] N. A. Worth, J. R. Dawson, J. A. Sidey, E. Mastorakos, Azimuthally forced flames in an annular combustor, Proc. Combust. Inst. 36 (2017) 3783-3790.

[20] E. Machover, E. Mastorakos, Experimental investigation on spark ignition of annular premixed combustors, Combust. Flame 178 (2017) 148-157.

[21] P. M. Allison, E. Mastorakos, Forced Response of Flames in a Bluff-Body Stabilized Annular Combustor, in: 55th AIAA Aerosp. Sci. Meet., pp. 1-12.

[22] A. G. Gaydon, H. G. Wolfhard, Flames, their structure, radiation, and temperature, Halsted Press, 1979.

[23] N. A. Worth, J. R. Dawson, Tomographic reconstruction of $\mathrm{OH}^{*}$ chemiluminescence in two interacting turbulent flames, Meas. Sci. Technol. 24 (2013). 
[24] R. Rajasegar, J. Choi, B. McGann, A. Oldani, T. Lee, S. D. Hammack, C. D. Carter, J. Yoo, Mesoscale burner array performance analysis, Combust. Flame 199 (2019) 324-337.

[25] K. Radhakrishnan, J. B. Heywood, R. J. Tabaczynski, Premixed turbulent flame blowoff velocity correlation based on coherent structures in turbulent flows, Combust. Flame 42 (1981) 19-33.

[26] J. Kariuki, Turbulent premixed flame stabilization and BlowOff, PhD Thesis, University of Cambridge, Cambridge, UK, 2012.

[27] S. J. Shanbhogue, S. Husain, T. Lieuwen, Lean blowoff of bluff body stabilized flames: Scaling and dynamics, Prog. Energy Combust. Sci. 35 (2009) 98-120.

[28] D. E. Cavaliere, J. Kariuki, E. Mastorakos, A comparison of the blow-off behaviour of swirl-stabilized premixed, non-premixed and spray flames, Flow, Turbul. Combust. 91 (2013) 347-372. 